\title{
Lesson: DESIGNING THE PEN BOX
}

Nguyen Thuy Tuong $\mathrm{Vy}^{1}$

${ }^{1}$ Affiliation not available

June 7, 2021

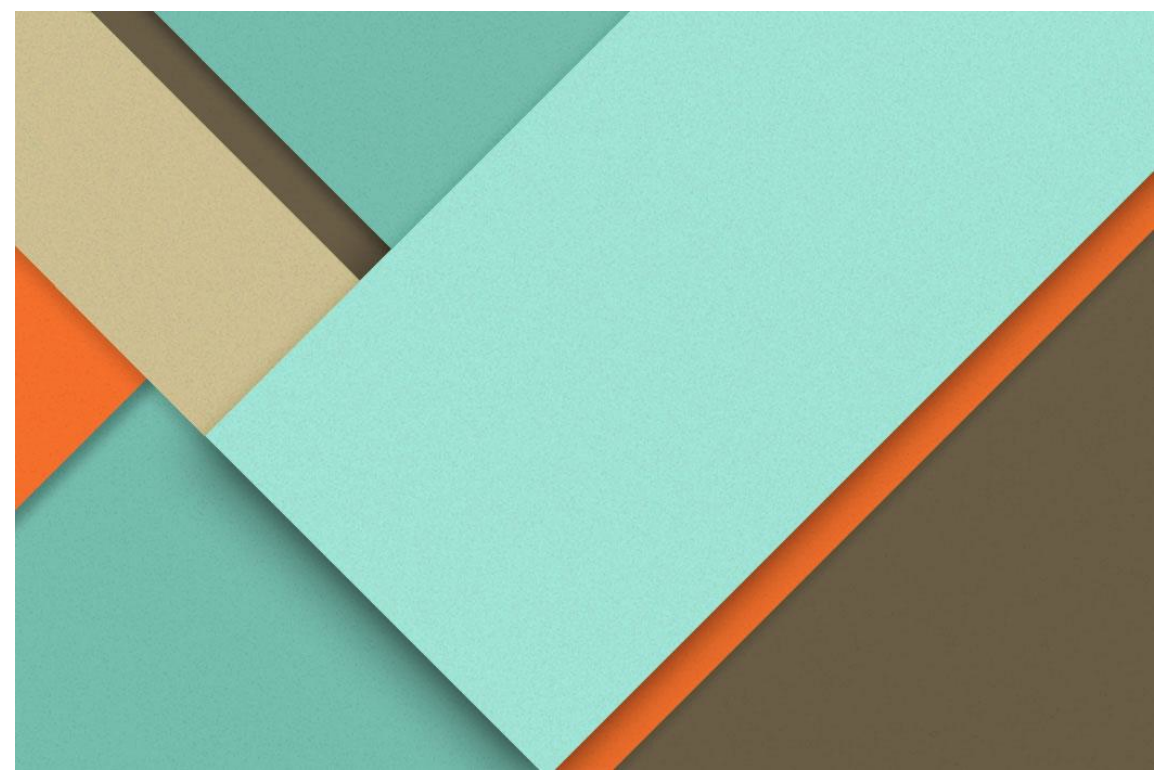

DESIGNING THE PEN BOX (50 minutes)

05.06 .2021

Nguyen Thuy Tuong Vy

LVtech

61, 2nd Street, Ward An Khanh, Thu Duc City

Hochiminh City, 700000

\section{About STEM lesson structure}

The structure of the lesson must follow the three stages of the student's activities. In fact, students will do 5 activities:

- Identify the problem 
- Research knowledge and propose solutions

- Discuss and select design options

- Fabrication of experimental equipment/models according to the selected plan

- Present the finished product, adjust if necessary

During the activity, students will experiment with each of their ideas, using a variety of approaches. When they make a mistake, the teacher must be the one to guide them to accept the mistake and learn from that mistake to try again and find the right solution. This is an important turning point to help build children's mindset that is not afraid of failure, willing to be wrong many times to develop themselves.

\section{Let students explore, discover and experience on their own}

STEM is about practice, reality. Therefore, throughout the lecture, the instructor must focus on leading the students to experience reality to the fullest extent. Students will have to conduct their own experiments and share information and ideas with each other to find the most optimal solution. This is an important factor to keep in mind when designing STEM lessons.

Students experience on their own

\section{Vivid lecture format}

STEM lessons must be built in an interesting and lively way to attract students. To be able to achieve such an effect, it requires all teachers at the school to work together to unify the way to teach in groups, to unify the process and products of STEM teaching. Only when the above factors are agreed will the lecture implementation be lively, students will be more interested in group practice sessions.

\section{Design STEM lessons based on what students already know}

If the teacher uses a completely new knowledge, the students will easily get bored because they do not understand the lesson and have difficulty in figuring out how to solve the problem. Therefore, teachers need to pay more attention to this factor. Besides, teachers can cooperate with other subject teachers to build integrated lessons, eliminating the gap between subjects. Thereby, students can know that Mathematics, Informatics,... are subjects that are bound to each other, but not independent subjects. 


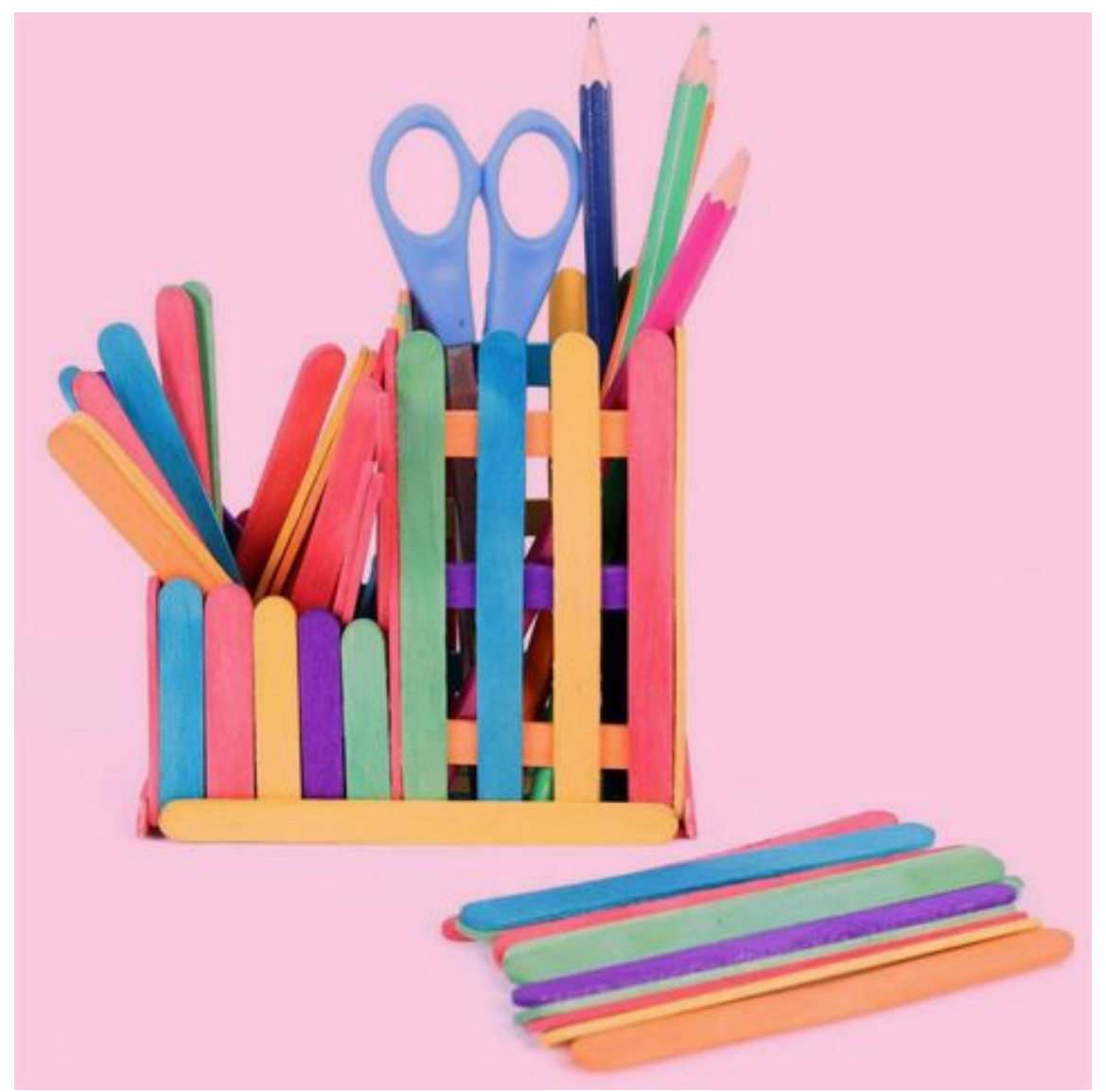




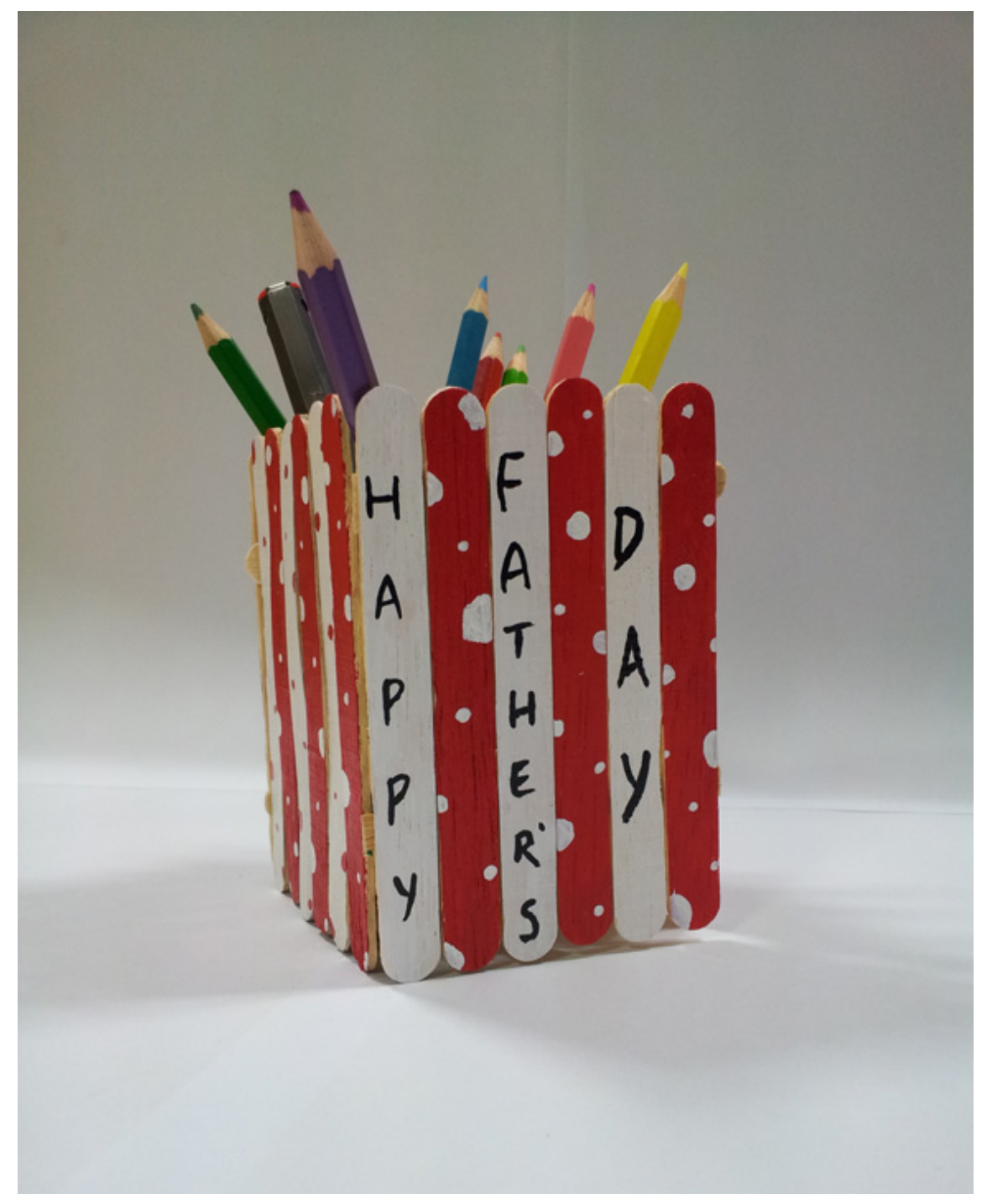




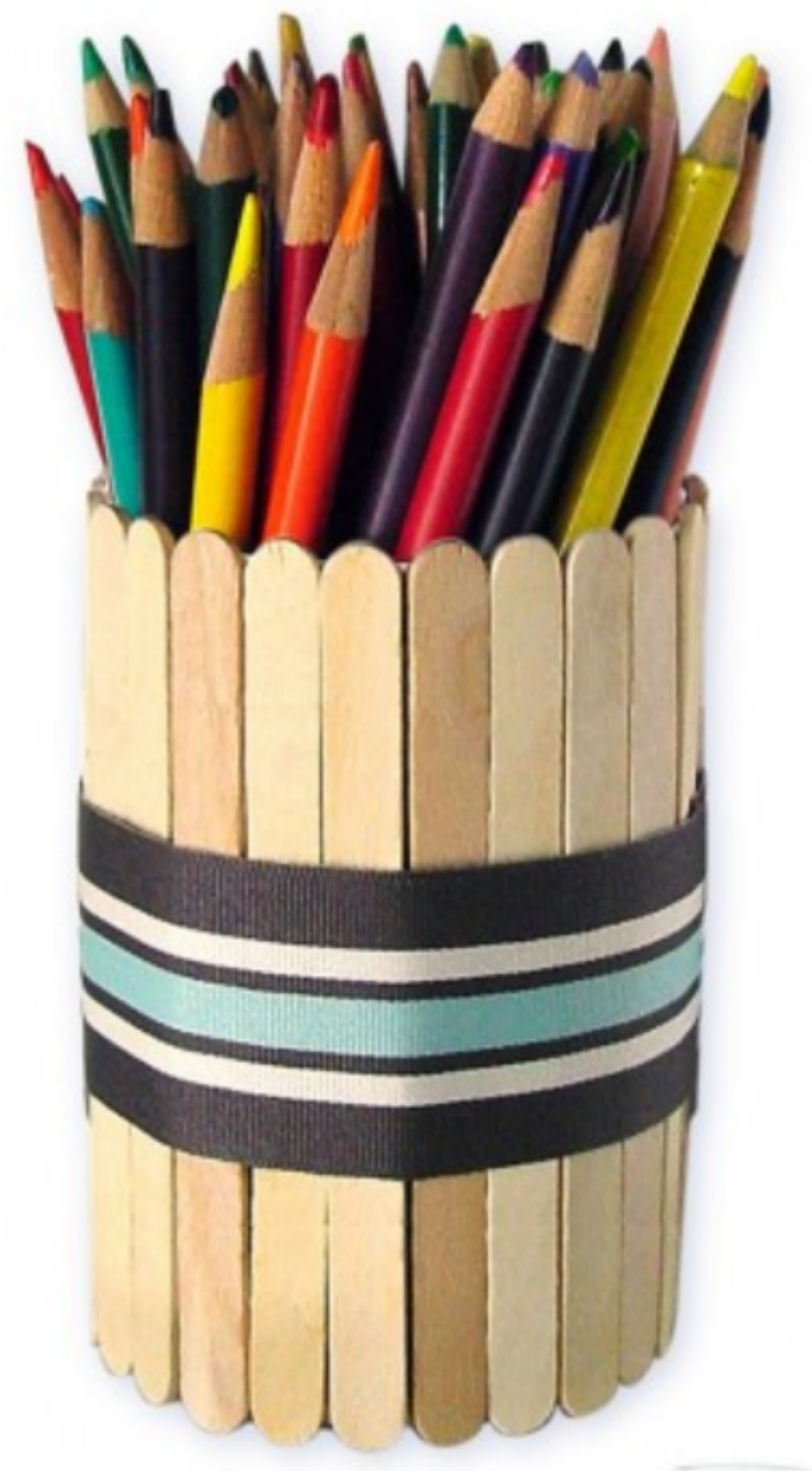

\section{DESIGNING THE PEN BOX AS THE FOLLOWING REQUIREMENTS}

+ Make a pen box that can hold the most number of pens (Check by putting each pen in the box, the box that holds more pens wins)

+ Only approved materials may be used.

+ If the number of pens is the same, the box that uses less material will get a higher score dim 
+ If the above factors are the same, the winning team result will be determined on the basis of the aesthetic vote of the whole class.

TOOL:

+50 ice cream sticks.

+1 sheet of A4 paper

+1 lighter, 1 candle

+1 candle glue

+1 scissors

GROUP ACTIVITIES FOR DESIGNING PEN BOXES AS DESIGNED TOOL:

+50 ice cream sticks.

+1 sheet of A4 paper

+1 lighter, 1 candle

+1 candle glue

+1 scissors

TIME: 50 MINUTES.

After finishing, the groups bring their products to the display table.

REPORT

GROUPS OF REPORTS

- The leader puts each pen in turn into his or her group's pen box to determine the number of pens to put in the box.

- Question.

Present the group's plan, showing the application of elements of mathematics, science, technology and engineering.

Explain the reasons for success and failure. 